\title{
Regulators Involved in Dickeya solani Virulence, Genetic Conservation, and Functional Variability
}

\author{
Marta Potrykus, ${ }^{1}$ Małgorzata Golanowska, ${ }^{1}$ Nicole Hugouvieux-Cotte-Pattat, ${ }^{2}$ and Ewa Lojkowska ${ }^{1}$ \\ ${ }^{1}$ Department of Biotechnology, Intercollegiate Faculty of Biotechnology, University of Gdansk and Medical University of \\ Gdansk, Kladki 24, 80-822 Gdansk, Poland; ²CNRS UMR5240 Microbiologie Adaptation et Pathogénie, Université de \\ Lyon 1, INSA de Lyon, F-69621Villeurbanne, France
}

Submitted 14 September 2013. Accepted 27 February 2014.

\begin{abstract}
Bacteria from the genus Dickeya (formerly Erwinia chrysanthemi) are plant pathogens causing severe diseases in many economically important crops. A majority of the strains responsible for potato disease in Europe belong to a newly identified Dickeya solani species. Although some ecological and epidemiological studies have been carried out, little is known about the regulation of $D$. solani virulence. The characterization of four $D$. solani strains indicates significant differences in their virulence on potato, although they are genetically similar based on genomic fingerprinting profiles. A phenotypic examination included an analysis of virulence on potato; growth rate in culture; motility; $\mathrm{Fe}^{3+}$ chelation; and pectate lyase, cellulase, protease, biosurfactant, and blue pigment production. Mutants of four $D$. solani strains were constructed by inactivating the genes coding either for one of the main negative regulators of $D$. dadantii virulence $(k d g R$, pecS, and pecT) or for the synthesis and perception of signaling molecules $(\operatorname{expI}$ and $\exp R)$. Analysis of these mutants indicated that PecS, PecT, and KdgR play a similar role in both species, repressing, to different degrees, the synthesis of virulence factors. The thermoregulator PecT seems to be a major regulator of $D$. solani virulence. This work also reveals the role of quorum sensing mediated by ExpI and ExpR in D. solani virulence on potato.
\end{abstract}

Bacteria from the genus Dickeya (formerly Erwinia chrysanthemi) are pathogens that cause severe diseases in many economically important crops. They have been listed in the top 10 most important bacterial plant pathogens based on their economic impact (Mansfield et al. 2012). The genus Dickeya consists of five species: Dickeya chrysanthemi, D. dadantii, D. dianthicola, D. zeae, and D. paradisiaca (Brady et al. 2012; Samson et al. 2005). Bacteria that belong to D. dadantii and $D$. zeae pose a threat to potato production in tropical climates (DeLindo and French 1981) while D. dianthicola, the pathogen of carnation, has become established in Europe over the last 40 years, causing black-leg and soft rot diseases in potato (Toth et al. 2011). The strains, isolated over the past 10 years from soft-rot- and black-leg-affected potato plants in numerous European countries, appeared to belong to a new Dickeya

Corresponding author: E. Lojkowska; Telephone: +48 58 5236426; Fax: +48 58 5236360; E-mail: ewa.lojkowska@biotech.ug.edu.pl

This article is in the public domain and not copyrightable. It may be freely reprinted with customary crediting of the source. The American Phytopathological Society, 2014. group (Slawiak et al. 2009b). Their characteristics, based on the disease symptoms, biochemical characterization, dnaX and recA sequencing, repetitive extragenic palindromic polymerase chain reaction (REP-PCR), and pulsed-field gel electrophoresis (PFGE) profiles, indicate a high level of homogeneity (Degefu et al. 2013; Slawiak at al. 2009b). Because these strains could not be classified into any previously described Dickeya spp., they were recently classified in a new species, D. solani (Van der Wolf et al. 2014). D. solani strains are highly virulent to potato plants and can initiate the disease from a low inoculum level (as low as 10 cells/tuber). They have a high optimal temperature range for disease development and growth (from 25 to $39^{\circ} \mathrm{C}$ ) and they spread more easily through the plant vascular system than other Dickeya spp. (Czajkowski et al. 2010; Toth et al. 2011).

Most of the information concerning the molecular mechanisms driving the initiation and spread of the soft rot disease comes from studies on a few Dickeya strains: D. dadantii 3937 (Hugouvieux-Cotte-Pattat et al. 1996) and Dickeya sp. strain EC16 (Tamaki et al. 1988). Bacteria can initially live on the surface and inside the intercellular spaces of the plant, without causing any disease symptoms (Pérombelon 1992). When they encounter favorable conditions such as warm temperature, high humidity, and low oxygen availability, they multiply and begin to produce pectinases, resulting in the initiation of the disease (Hugouvieux-Cotte-Pattat et al. 1996; Pérombelon 2002). Bacteria from the genus Dickeya can invade and destroy the plant tissue via the coordinated expression of several genes encoding virulence factors, mainly plant cell-wall-degrading enzymes (PCWDE). D. dadantii strain 3937 secretes at least nine endopectate lyases and three accessory pectinases (Hassan et al. 2013; Hugouvieux-Cotte-Pattat et al. 1996; Kazemi-Pour et al. 2004), three proteases (Kazemi-Pour et al. 2004), and a cellulase (Py et al. 1991). Other factors can help bacteria to survive in harsh environments such as the surface of the plant, water, or soil. These factors include bacterial features such as iron capture, mobility, and the production of biosurfactants or pigments (Enard et al. 1988; Pérombelon 2002; Raaijmakers et al. 2009).

The bacteria from the genus Dickeya are able to sense their environment, and the induction of production of PCWDE and other virulence factors depends essentially on this ability. The appropriate production and secretion of these molecules requires an elaborate regulatory network that can act in a concerted manner in response to complex environmental signals (Charkowski et al. 2012; Hugouvieux-Cotte-Pattat et al. 1996; Kepseu et al. 2010; Reverchon and Nasser 2013). Studies on the regulation of Dickeya virulence led to the identification of 10 major regulators: namely, KdgR, PecS, PecT, CRP, H-NS, Fis, Fur, 
GacA, SlyA, and MfbR (Charkowski et al. 2012). Moreover, these studies suggest the existence of quorum-sensing (QS) mechanisms: an acyl-homoserine lactone (AHL) regulation system (ExpR and ExpI) (Reverchon et al. 1998) and the recently discovered Vfm system, responsible for the secretion and sensing of an as-yet-unidentified molecule (Nasser et al. 2013). These regulators not only trigger the synthesis and secretion of PCWDE but also that of other virulence factors such as exopolysaccharide production and motility (Charkowski et al. 2012).

In the $D$. dadantii 3937 virulence regulatory network, there are three principal negative transcriptional regulators: KdgR, PecT, and PecS (Condemine and Robert-Baudouy 1987; Praillet et al. 1996; Surgey et al. 1996). These three elements act independently on PCWDE synthesis and secretion. The KdgR transcriptional repressor is released from its target DNA in the presence of pectin degradation products such as 2-keto-3-deoxygluconate (Hugouvieux-Cotte-Pattat et al. 1996). The KdgR regulon includes the genes encoding proteins involved in pectin degradation, the catabolism of rhamnogalacturonides, the Out secretion system, some glycolytic steps, and sugar efflux transport (Rodionov et al. 2004). The PecT transcriptional regulator is involved in the regulation of PCWDE and exopolysaccharide synthesis. It was recently proposed that PecT functions as a thermoregulator of the target genes (Hérault et al. 2014). Variations in PecT intracellular concentrations have significant effects on these genes and PecT production is repressed by the nucleoid-associated protein $\mathrm{H}-\mathrm{NS}$ and its own autoregulation but is activated by KdgR (Nasser and Reverchon 2002; Rodionov et al. 2004). PecS is a global regulator of the symptomatic phase of the disease. It directs the production and secretion of PCWDE and also the production of indigoidine, biosurfactant, and flagella (Hommais et al. 2008; Mhedbi-Hajri et al. 2011). The signal responsible for PecS derepression is still unknown. The QS system mediated by ExpR and ExpI can activate pecS expression. Reciprocally, $\mathrm{PecS}$ is able to repress the expression of $\operatorname{expR}$ and of the Vfm cluster (Nasser et al. 2013). D. dadantii 3937 and D. solani are able to produce three different AHL: N-(3-oxohexanoyl)-homoserine lactone (3-oxo-C6-HSL), N-(hexanoyl)-homoserine lactone (C6-HSL) and $\mathrm{N}$-(3-oxooctanoyl)-homoserine lactone (3-oxo-C8-HSL) (Crepin et al. 2012). The QS mechanism involving ExpR and ExpI has been shown to be of little importance in $D$. dadantii

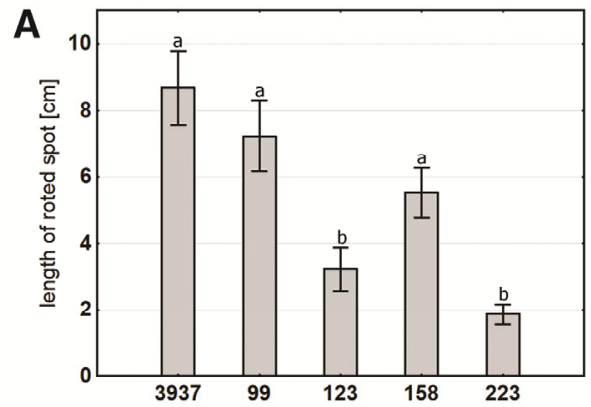

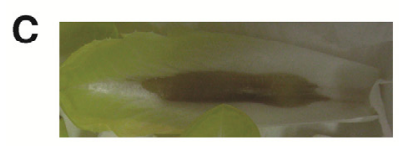

IFB0099

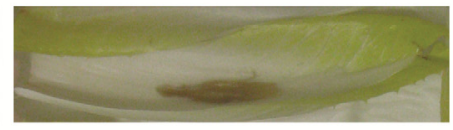

IFB0123
3937 (Mhedbi-Hajri et al. 2011) but it plays a significant role in the mobility and virulence of $D$. zeae EC1 (Hussain et al. 2008).

Little is known about the regulation of $D$. solani virulence. Here, we report the characterization of four D. solani strains that differ significantly in their level of virulence on potato although they appear to be genetically similar based on REPPCR and PFGE profiles. The regulation of D. dadantii 3937 virulence is well documented but it remains unclear whether this regulation is similar in other Dickeya spp. To investigate the effect in $D$. solani of certain virulence regulatory factors, mutants of four $D$. solani strains were constructed by inactivating the genes coding either for one of the main virulence negative regulators $(k d g R$, pecS, and pecT) or for the synthesis and perception of signaling molecules $(\operatorname{expI}$ and $\exp R)$. To our knowledge, this is the first report detailing the regulatory network controlling the virulence of $D$. solani strains.

\section{RESULTS}

\section{Genetic characterization of four $D$. solani strains with different virulence levels.}

The four D. solani wild-type strains (IFB0099, IFB0123, IFB0158, and IFB0223) were selected on the basis of their differential abilities to cause disease symptoms on potato tubers and chicory leaves (Fig. 1). As regards their genetic characterization, these strains appeared to be homogeneous based on their similar banding patterns in REP-PCR, with a REP primer pair, and in PFGE (Fig. 2). The dnaX sequence was $100 \%$ identical in the four tested strains and, furthermore, it was identical to other D. solani dnaX sequences available in the GenBank database. Three of the examined strains (IFB0099, IFB0123, and IFB0158) were isolated from symptomatic potato plants in Poland or The Netherlands, while the strain IFB0223 was derived from the rhizosphere of asymptomatic potato plant in Germany. Statistical analysis of the diseases symptoms showed that the most virulent $D$. solani strains on both chicory leaves and potato tubers were IFB0099 and IFB0158 isolated in Poland. The strains IFB0123 and IFB0223 were less virulent. On the potato tubers, strain IFB0123, isolated in The Netherlands, caused intermediate disease symptoms while IFB0223, isolated in Germany, showed the lowest virulence (Fig. 1).
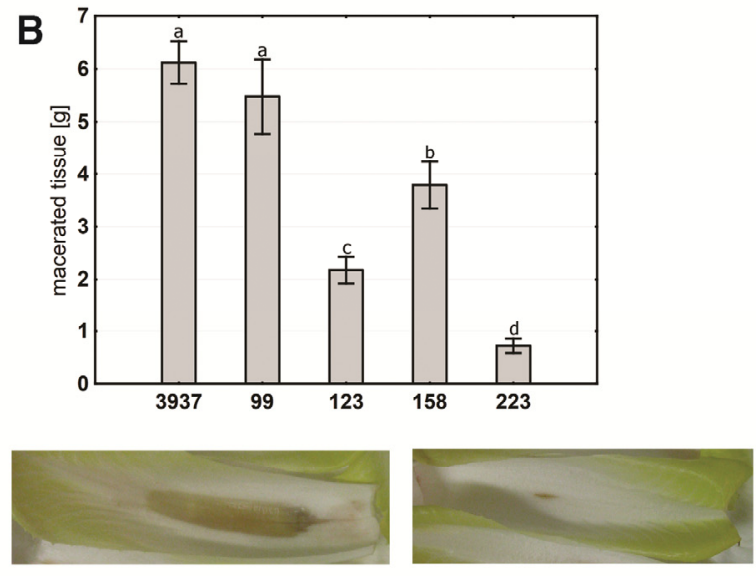

IFB0158

Fig. 1. Virulence of the selected Dickeya solani strains and of D. dadantii 3937 on chicory leaves and potato tubers. A, Virulence on chicory leaves 24 h postinoculation, measured by the length of the macerated area $(\mathrm{cm})(n=3 ; F=11.6) ; \mathbf{B}$, virulence on potato tubers in grams of macerated tissue, $48 \mathrm{~h}$ postinoculation; $(n=6 ; F=34.2)$; C, examples of symptoms observed on chicory leaves. Strains used are D. dadantii 3937 (3937) and the D. solani strains IFB0099 (99), IFB0123 (123), IFB0158 (158), and IFB0223 (223). For both plant species, experiments were performed twice. Within each figure, columns with different letters are significantly different based on an analysis of variance followed by Fisher test at $P<0.05$, with the $F$ values indicated above for each test. 
We performed further characterization of the four selected D. solani strains together with D. dadantii 3937 used for comparison. D. dadantii 3937 is the Dickeya strain that has been the most extensively analyzed (Hugouvieux-Cotte-Pattat et al. 1996). Its genome has been sequenced (Glasner et al. 2011), regulation of the virulence program has been described (Reverchon and Nasser 2013), and a range of well-characterized mutants is available.

\section{Phenotypic characterization of the $D$. solani strains.}

First of all, the growth curve of each strain in Luria-Bertani (LB) medium was determined (Fig. 3A). For statistical analysis, we compared the cell densities obtained after $16 \mathrm{~h}$ (early stationary phase). The two D. solani strains that appeared to be the most virulent (IFB0099 and IFB0158) grew to higher densities than the other strains. Strains IFB0123 and D. dadantii 3937 grew to intermediate densities. The least virulent strain (IFB0223) grew to the least density.

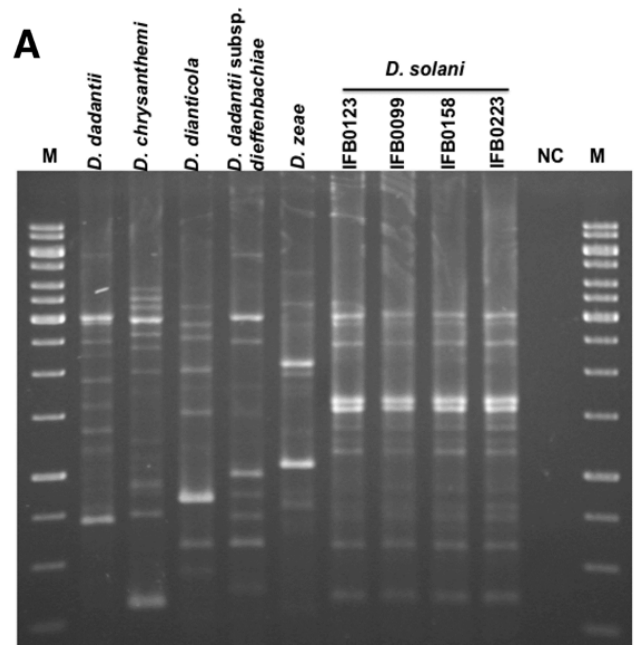

Statistical analysis of the growth rates of these strains (Fig. 3B) divided them into two groups. The two most virulent strains (IFB0099 and IFB0158) and D. dadantii 3937 grouped together, with growth rates of $0.33,0.32$, and 0.39 per hour, respectively. The second group contained IFB0123 and IFB0223, with growth rates of 0.24 and 0.18 per hour, respectively.

The production of PCWDE was then analyzed. The total pectate lyase activity produced by the strains differed (Fig. 4A and B). In noninduced conditions, the most virulent strain, IFB0099, showed a high basal pectate-lyase activity, approximately fourfold higher than $D$. dadantii 3937 . The pectate lyase activities of the other $D$. solani strains were not significantly different from that of $D$. dadantii 3937 (Fig. 4A). When polygalacturonate was added to induce pectinase production (induced conditions), pectate-lyase activity increased for all strains and IFB0099 showed significantly higher activity than the other strains (Fig. 4B).

The protease production of IFB0099 was also higher than that of the tested strains (Fig. 4C). The protease production

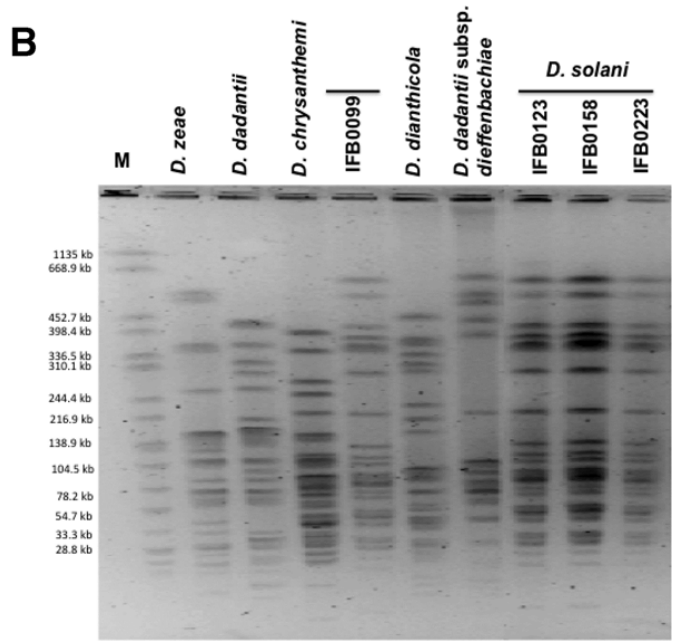

Fig. 2. Repetitive extragenic palindromic polymerase chain reaction (REP-PCR) and pulsed-field gel electrophoresis (PFGE) profiles of Dickeya strains. A, REP-PCR profiles obtained with the use of REP1 RI and REP 2I primers. B, PFGE profiles obtained by digestion of genomic DNA with XbaI. Strains used are Dickeya dadantii IFB0010, D. chrysanthemi IFB0055, D. dianthicola IFB0103, D. dadantii subsp. dieffenbachiae IFB0113, D. zeae IFB0119, and the four $D$. solani strains IFB0099, IFB0123, IFB0158, and IFB0223. NC = negative control, M = DNA size marker (1-kb ladder; Fermentas) for A and genomic DNA of Salmonella enterica ser. braenderup digested with XbaI for B.
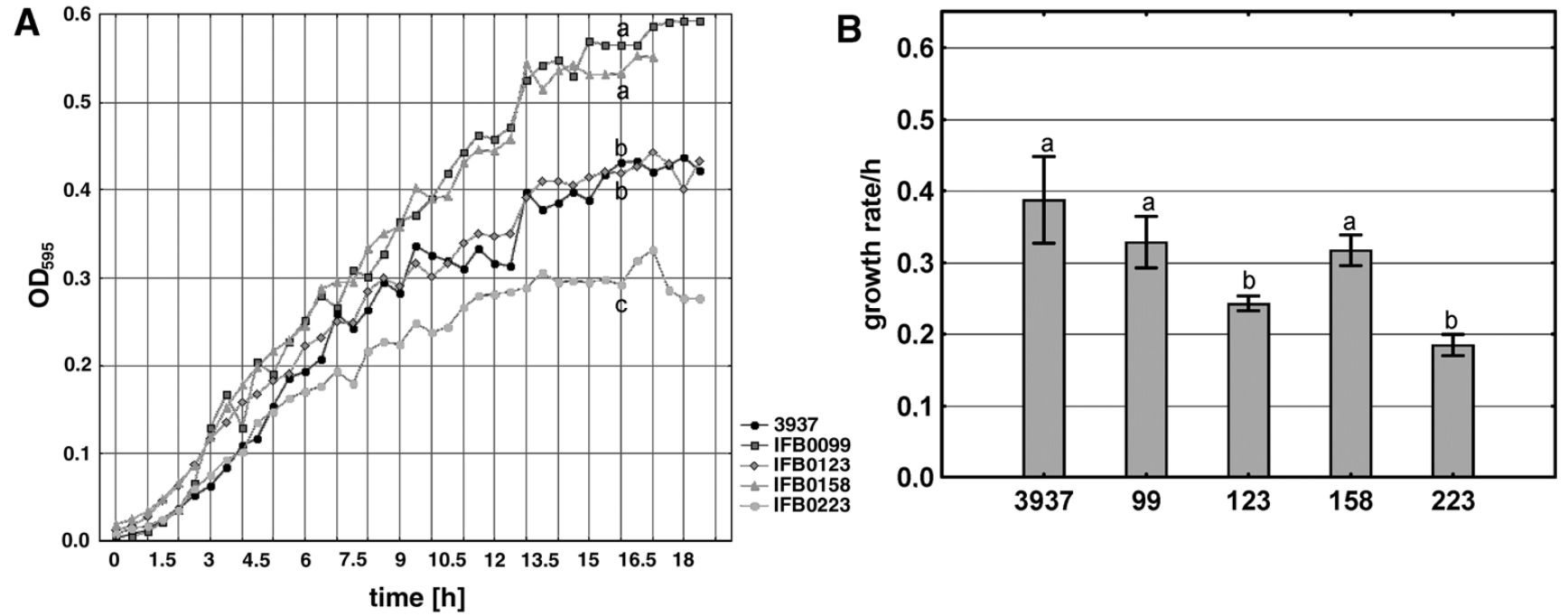

Fig. 3. Growth of Dickeya solani and $D$. dadantii wild-type strains. Bacteria were grown in Luria-Bertani medium at $28^{\circ} \mathrm{C}$ and growth was measured by optical density at $595 \mathrm{~nm}\left(\mathrm{OD}_{595}\right)$. A, Growth curve is given as $\mathrm{OD}_{595}$ values in the function of time $(\mathrm{h})(n=2, F=49.4)$. For simplicity and clarity of the graph, standard errors were excluded. $\mathrm{OD}_{595}$ values at $16 \mathrm{~h}$ were compared. B, Growth rate of the bacterial strains $(n=2, F=4.3)$. Strains used are $D$. dadantii 3937 and the D. solani strains IFB0099, IFB0123, IFB0158, and IFB0223. Experiments were repeated twice. Within B, columns with different letters are significantly different when assayed with analysis of variance followed by Fisher test at $P<0.05$, with the $F$ values indicated above for each test. 
was observed for other strains, except for IFB0223, for which no protease activity was detected. A strong difference between $D$. solani strains and $D$. dadantii was observed for cellulase production. The four $D$. solani strains showed a significantly higher cellulase production than $D$. dadantii 3937 (Fig. 4D). In contrast, the ability of $D$. solani strains to chelate $\mathrm{Fe}^{3+}$ ions was significantly lower than that of D. dadantii 3937 (Fig. 4E). None of the strains demonstrated biosurfactant production in the tested conditions (data not shown). Their swarming ability was low and no difference was observed between the $D$. solani and $D$. dadantii strains (data not shown). However, the swimming ability of D. solani IFB0099 was approximately $25 \%$ higher than that of the other strains (Fig. 4F).

The production of signaling molecules belonging to the AHL family was investigated using different Escherichia coli biosensor strains (Andersen et al. 2001; Winson et al. 1998). For all the $D$. dadantii 3937 and $D$. solani strains, the production of C6-HSL and C8-HSL was detected with E. coli HB101/
pSB401. Use of two other biosensor strains, E. coli HB101/ pSB534 and E. coli HB101/pSB1075, indicated that none of the tested Dickeya strains were able to produce C4-HSL, C10HSL, C12-HSL, and C14-HSL (data not shown).

\section{Infection of the $D$. solani strains}

with the bacteriophage phi-EC $\mathbf{C}_{2}$.

D. dadantii 3937 is known to be sensitive to the bacterio-

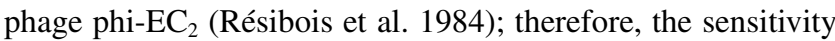
of $D$. solani strains to this bacteriophage was analyzed. Using stocks prepared by infection of $D$. dadantii 3937, the $D$. solani strains appeared to be less sensitive to phage phi-EC $\mathrm{E}_{2}$ than $D$. dadantii 3937 and they showed different degrees of sensitivity to infection in the serial dilution test. With strains IFB0123 and IFB0223, the number of phage plaques was similar to that obtained with $D$. dadantii 3937. Compared with these three strains, approximately 100-fold lower numbers of plaques were observed with strains IFB0099 and IFB0158.
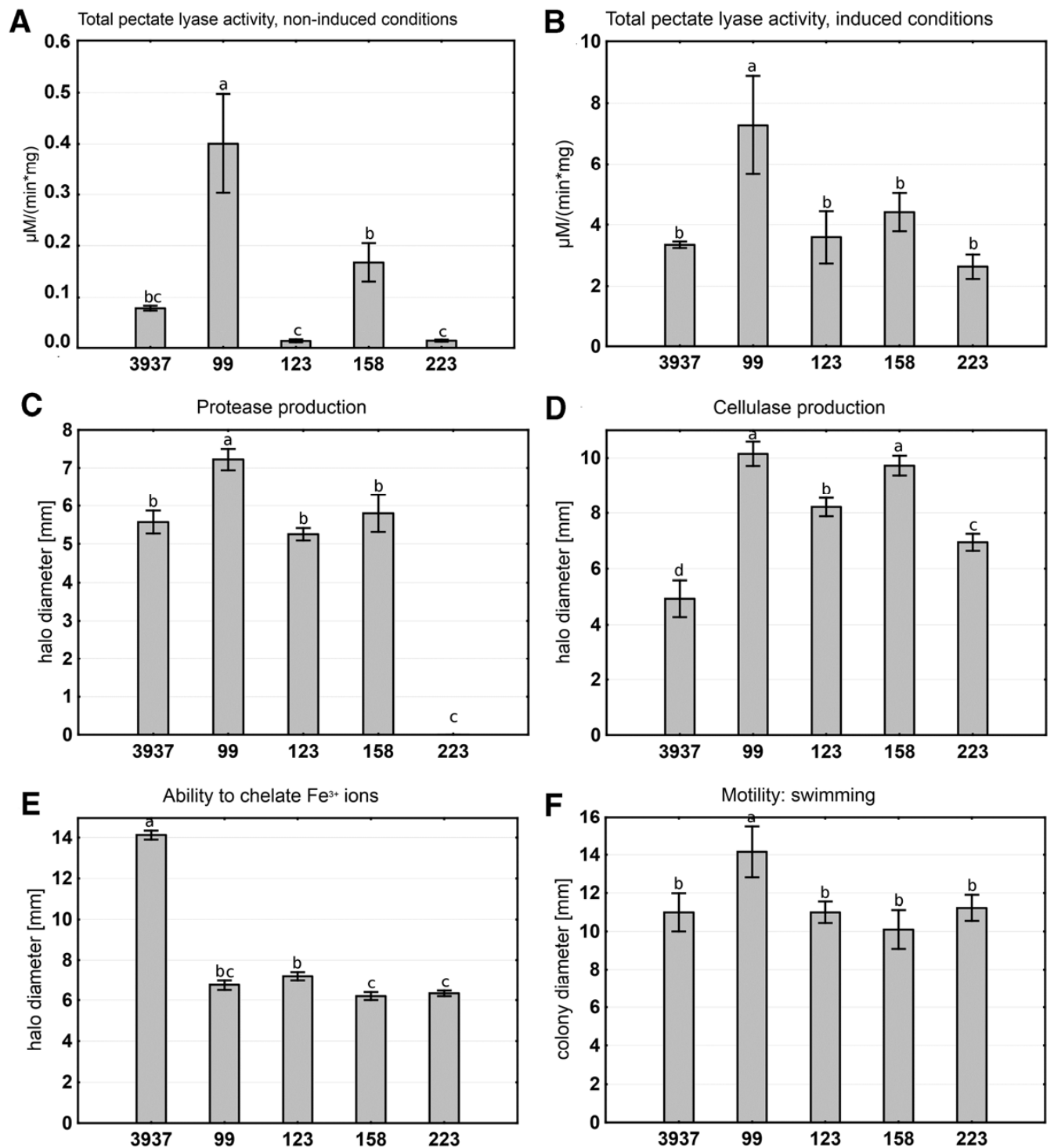

Fig. 4. Phenotypic characterization of four wild-type Dickeya solani strains and comparison with $D$. dadantii 3937. A, Total pectate lyase specific activity $\left(\mu \mathrm{mol} \mathrm{min} \mathrm{mg}^{-1}\right)$ in noninduced conditions $(n=4 ; F=11.5)$. B, Total pectate lyase specific activity $\left(\mu \mathrm{mol} \mathrm{min}^{-1} \mathrm{mg}^{-1}\right)$ in induced conditions (induction by addition of polygalacturonate) $(n=3 ; F=4.1)$. C , Protease production was estimated by the diameter $(\mathrm{mm})$ of the haloes observed on the detection plates $(n=4$; $F=66.3)$; D, Cellulase production was estimated by the diameter $(\mathrm{mm})$ of the haloes observed on the detection plates $(n=7 ; F=23.0)$. E, Iron chelating capacity was estimated by the diameter $(\mathrm{mm})$ of the haloes observed around colonies $(n=4 ; F=254)$. F, Motility was estimated by the diameter (mm) of the spread of the colonies $(n=5 ; F=2.7)$. All of the experiments were performed twice. Strains used were D. dadantii 3937 (3937) and the D. solani strains IFB0099 (99), IFB0123 (123), IFB0158 (158), and IFB0223 (223). Within each figure, columns with different letters are significantly different when assayed with analysis of variance followed by Fisher test at $P<0.05$, with the $F$ values indicated above for each test. 
The bacteriophage phi-EC $\mathrm{EC}_{2}$ is classically used to transfer selectable mutations by transduction in D. dadantii 3937 (Résibois et al. 1984). Thus, transduction of a chloramphenicol (Cm) resistance marker $\left(\mathrm{Cm}^{\mathrm{R}}\right)$ on the $D$. solani chromosome was tested using phi-EC $\mathrm{E}_{2}$ stocks obtained by infection of different D. dadantii mutants containing a $\mathrm{Cm}$ insertion in a regulatory gene (A1077, A2174, A3009, A3148, and A3494) (Table 1). Compared with the number of transductants obtained for strain 3937 , used as the control (100\%), the levels of $\mathrm{Cm}^{\mathrm{R}}$ transductants obtained for the D. solani strains corresponded to $57 \pm 17$, $26 \pm 9,16 \pm 5$, and $7 \pm 4 \%$ for IFB0223, IFB0123, IFB0099, and IFB0158, respectively. The statistical analysis using analysis of variance (ANOVA) $(F=99.6)$ followed by Fisher posthoc test showed that the differences in the efficiencies of transduction between the strains are significant and divided them into two groups: the most-sensitive strains IFB0223 and IFB0123 and the less-sensitive strains IFB0099 and IFB0158. Thus, the efficiency of transduction correlates well with the level of sensitivity observed for each strain using plaque formation in the serial dilution test.

\section{Conservation of virulence regulatory genes and construction of mutants.}

One aim of this study was to analyze the role of some of the regulatory genes previously identified in $D$. dadantii 3937 in the virulence of the $D$. solani strains. First, we checked, using

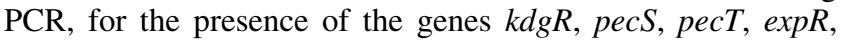
and $\operatorname{expI}$ in the four $D$. solani strains. The five genes were present in the four D. solani strains. Sequencing of the $k d g R$ PCR products demonstrated $100 \%$ identity between the $k d g R$ genes of the four D. solani strains. The availability of the genome sequence of IPO2222 (IFB0123), (Pritchard et al 2013) allowed us to evaluate the sequence of the different genes in this strain. These sequences were also obtained by searching the draft genome sequences of IFB0099 and IFB0223 (unpublished data). Again, the sequences of $k d g R, p e c S, p e c T, \operatorname{expR}$, and $\operatorname{expI}$ were found to be $100 \%$ identical among the strains examined.

We compared the sequences of the regulatory genes of the four different $D$. solani strains with those of other Dickeya spp.: D. dadantii 3937, D. chrysanthemi 1591, D. zeae Ech586, and D. paradisiaca Ech703 (GenBank, with corrections for

Table 1. Bacterial strains used in this study

\begin{tabular}{|c|c|c|c|}
\hline Strain $^{a}$ & Species & Description $^{b}$ & Source, reference ${ }^{c}$ \\
\hline \multicolumn{4}{|l|}{ Wild-type strains } \\
\hline 3937 & Dickeya dadantii & Wild-type & Kotoujansky et al. 1982 \\
\hline IFB0010 & D. dadantii & Wild-type, type strain & CFBP1269 \\
\hline IFB0055 & D. chrysanthemi & Wild-type, type strain & CFBP2048 \\
\hline IFB0103 & D. dianthicola & Wild-type, type strain & CFBP1200 \\
\hline IFB0113 & D. dadantii subsp. dieffenbachiae & Wild-type, type strain & CFBP2051 \\
\hline IFB0119 & D. zeae & Wild-type, type strain & CFBP2052 \\
\hline IFB0099 & D. solani & Wild-type, Poland & Slawiak et al. 2009a \\
\hline IFB0123 & D. solani & Wild-type, The Netherlands & IPO2222, Van der Wolf et al. 2014 \\
\hline IFB0158 & D. solani & Wild-type, Poland & This work \\
\hline IFB0223 & D. solani & Wild-type, Germany & Weinert et al. 2010 \\
\hline \multicolumn{4}{|l|}{ Mutant strains } \\
\hline A1077 & D. dadantii & 3937 rafR lacB $k d g R:: \mathrm{Cm}$ & Rodionov et al. 2004 \\
\hline A2174 & D. dadantii & 3937 rafR lacB pecT::Cm & Surgey et al. 1996 \\
\hline A3009 & D. dadantii & 3937 rafR lacB expR::Cm & Nasser et al. 1998 \\
\hline A3148, & D. dadantii & 3937 rafR lacB expI::Cm & Nasser et al. 1998 \\
\hline A3494 & D. dadantii & 3937 rafR lacB pecS::Cm & Nasser et al. 1999 \\
\hline 3937R & D. dadantii & $3937 k d g R:: \mathrm{Cm}$ & This work \\
\hline $3937 \mathrm{~S}$ & D. dadantii & 3937 pecS::Cm & This work \\
\hline $3937 \mathrm{~T}$ & D. dadantii & 3937 рест::Cm & This work \\
\hline $3937 \mathrm{E}$ & D. dadantii & $3937 \operatorname{expR}:: \mathrm{Cm}$ & This work \\
\hline IFB0099R & D. solani & IFB0099 kdgR::Cm & This work \\
\hline IFB0123R & D. solani & IFB0123 kdgR::Cm & This work \\
\hline IFB0158R & D. solani & IFB0158 kdgR::Cm & This work \\
\hline IFB0223R & D. solani & IFB0223 kdgR::Cm & This work \\
\hline IFB0099S & D. solani & IFB0099 pecS::Cm & This work \\
\hline IFB0123S & D. solani & IFB0123 pecS::Cm & This work \\
\hline IFB0158S & D. solani & IFB0158 pecS::Cm & This work \\
\hline IFB0223S & D. solani & IFB0223 pecS::Cm & This work \\
\hline IFB0099T & D. solani & IFB0099 pecT::Cm & This work \\
\hline IFB0123T & D. solani & IFB0123 pecT::Cm & This work \\
\hline IFB0158T & D. solani & IFB0158 pecT::Cm & This work \\
\hline IFB0223T & D. solani & IFB0223 ресT::Cm & This work \\
\hline IFB0099E & D. solani & IFB0099 $\operatorname{expR::Cm~}$ & This work \\
\hline IFB0123E & D. solani & IFB0123 $\operatorname{expR}:: \mathrm{Cm}$ & This work \\
\hline IFB0158E & D. solani & IFB0158 $\exp R:: \mathrm{Cm}$ & This work \\
\hline IFB0223E & D. solani & IFB0223 $\operatorname{expR::Cm~}$ & This work \\
\hline IFB0099I & D. solani & IFB0099 expI::Cm & This work \\
\hline IFB0123I & D. solani & IFB0123 expI::Cm & This work \\
\hline IFB0158I & D. solani & IFB0158 expI::Cm & This work \\
\hline IFB0223I & D. solani & IFB0223 expI::Cm & This work \\
\hline \multicolumn{4}{|c|}{ Harboring plasmids (AHL) } \\
\hline HB101/pSB401 & Escherichia coli & Tet $^{\mathrm{R}}$ luxRI'::luxCDABE (pACYC184-derived) & Winson et al. 1998 \\
\hline HB101/pSB534 & E. coli & $\mathrm{Amp}^{\mathrm{R}}$ lasRI::luxBCDAE & Andersen et al. 2001 \\
\hline HB101/pSB1075 & E. coli & Tet $^{\mathrm{R}}$ lasRI::luxBCDAE & Winson et al. 1998 \\
\hline
\end{tabular}

${ }^{\text {a }}$ IFB = Intercollegiate Faculty of Biotechnology UG\&MUG collection numbers, A = Microbiologie Adaptation et Pathogénie collection numbers, and AHL = acyl-homoserine lactone biosensors.

${ }^{\mathrm{b}} \mathrm{Cm}=$ chloramphenicol; $\mathrm{Tet}^{\mathrm{R}}$ and $\mathrm{Amp}^{\mathrm{R}}=$ resistant to tetracycline and ampicillin.

${ }^{\mathrm{c}}$ IPO = International Plant Protection collection numbers and CFBP $=$ French Collection of Plant-Associated Bacteria. 
strain classification by Pritchard and associates [2013]) and $D$. solani IPO2222 (Pritchard et al. 2013). For each gene studied, the $D$. solani sequences presented the highest percentage of identity with sequences of $D$. dadantii 3937 , with $94 \%$ identity for $k d g R, 95 \%$ for $p e c S, 92 \%$ for $p e c T, 95 \%$ for $\operatorname{expR}$, and $95 \%$ for expI. The percent identity varied from 75 to $88 \%$ between $D$. solani and the three other Dickeya spp. (D. chrysanthemi, D. zeae, and D. paradisiaca), depending on the gene. A major difference was observed for the D. paradisiaca Ech703 genome, which lacks sequences similar to $\exp R$ and expI. These sequence homology data suggest a high conservation of the genes studied among the D. solani strains and a greater similarity between $D$. solani and $D$. dadantii genomes than between $D$. solani and any other sequenced Dickeya sp.

$D$. solani mutants affected in each of the regulatory genes were constructed by transduction (Table 1) in order to analyze the effect of gene inactivation. The $D$. dadantii 3937 mutants used in this study were prepared by transduction in the same conditions as the $D$. solani mutants to facilitate a comparison between the strains. Only the phenotypes for which we observed differences between the mutants and the wild-type strains are described. For example, cellulase production and swarming ability are not discussed because they did not show statistically significant differences between the mutants and the corresponding wild-type strains (data not shown).

\section{Phenotypes of the $D$. solani $k d g R$ mutants.}

The $k d g R$ mutation in both the $D$. solani strains and $D$. $d a$ dantii 3937, did not affect the ability to macerate potato tubers (Fig. 5A). For all the strains, the pectate-lyase-specific activity of the $k d g R$ mutants measured in noninduced conditions was un- regulated compared with the corresponding wild-type strain (Fig. 5B). The differences were significant, except for IFB0158. In the presence of polygalacturonate as inducer, the pectatelyase-specific activity in the $k d g R$ mutants was not significantly affected compared with the activity measured in the corresponding parental strain (Fig. 5C). Protease production was unregulated in the $k d g R$ mutants of $D$. dadantii 3937 and IFB0223 (Fig. 6A). The ability to chelate $\mathrm{Fe}^{3+}$ ions slightly increased in the $k d g R$ mutants of 3937 and IFB0158 (Fig. 6B).

\section{Phenotypes of the $D$. solani pecS mutants.}

A characteristic of all the pecS mutants was the overproduction of a blue pigment that was examined visually. This production was the highest in IFB0099, intermediate in IFB0158 and 3937, and very low in the IFB0123 and IFB0223 pecS mutants. The pecS mutation increased the ability of strains IFB0123 and IFB0158 to macerate potato tubers, whereas there was no significant change in the other strains (Fig. 5A). The basal pectate-lyase-specific activity significantly increased in the pecS mutants of $D$. dadantii 3937 and IFB0123 (Fig. $5 B)$. Pectate lyase activity in induced conditions was unregulated in most of the pecS mutants (Fig. 5C). This up regulation in induced conditions was significant for 3937, IFB0123, and IFB0158. Protease production increased only in the pecS mutant of D. dadantii 3937 and IFB0223 (Fig. 6A). The ability to chelate $\mathrm{Fe}^{3+}$ ions was unregulated in all pecS mutants but IFB0223 (Fig. 6B). Swimming ability significantly increased in the pecS mutants of $D$. dadantii 3937, IFB0099, and IFB0123 (Fig. 6C). In addition, the production of biosurfactant became visible in the pecS mutants of $D$. dadantii 3937 and of the $D$. solani strains, except IFB0223 (data not shown).

A Potato pathogenicity $(48 \mathrm{~h})$
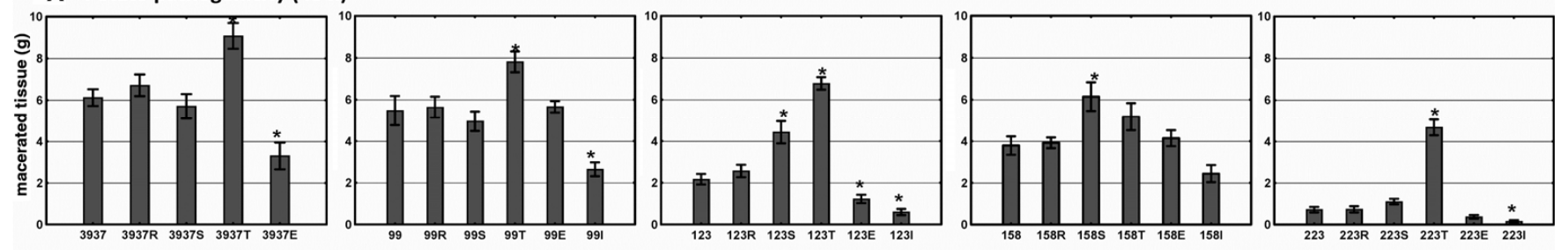

B Pectate-lyase activity in noninduced conditions
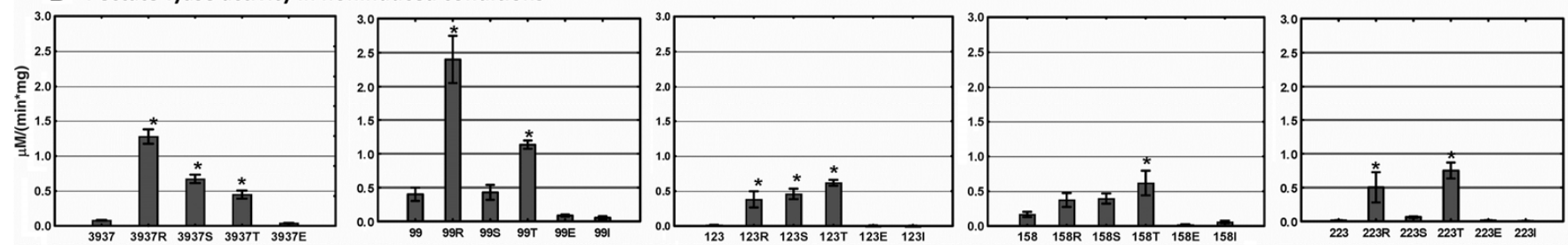

C Pectate lyase activity in induced conditions
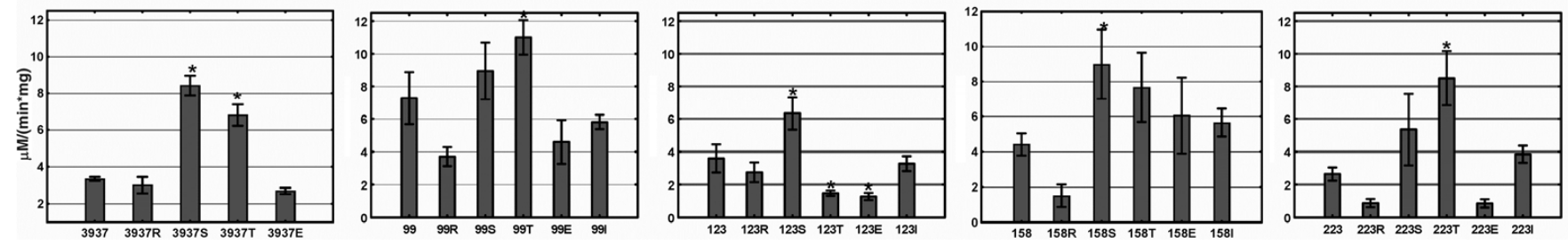

Fig. 5. Phenotypic characteristics of the mutants compared with the parental strains. A, Virulence on potato tubers, in grams of macerated tissue $48 \mathrm{~h}$ postinoculation ( $n=9$; for each graph, $F=13.7,14.6,50.8,5.7$, and 87.7, respectively). B, Total pectate lyase specific activity $\left(\mu \mathrm{mol} \mathrm{min}^{-1} \mathrm{mg}^{-1}\right)$ in noninduced conditions; $\left(n=3\right.$; for each graph, $F=82.9,33.5,26.1,5.5$, and 10.7 , respectively). C, Total pectate lyase specific activity $\left(\mu \mathrm{mol} \mathrm{min}^{-1} \mathrm{mg}^{-1}\right)$ in induced conditions (induction by addition of polygalacturonate) $(n=3$; for each graph, $F=38.9,4.3,7.2,3.5$, and 6.8 , respectively). Presented experiments were performed twice. Strains were Dickeya dadantii 3937 (3937); the D. solani strains IFB0099 (99), IFB0123 (123), IFB0158 (158) and IFB0223 (223); and the derived mutants indicated with $\mathrm{R}$ for the $k d g R:: \mathrm{Cm}$ mutants (e.g., 99R), $\mathrm{S}$ for the pec $S:: \mathrm{Cm}$ mutants (e.g., 99S), T for the pecT::Cm mutants (e.g., 99T), E for the expR::Cm mutants (e.g., 99E), and I for the expI::Cm mutants (e.g., 99I). For each figure, the $F$ values resulting from analysis of variance followed by a Fisher test are indicated above, with asterisks indicating mutants that differed significantly from the corresponding wild-type strain $(P<0.05)$. 
Phenotypes of the $D$. solani pecT mutants.

The pecT mutants of all the Dickeya strains showed higher virulence on potato tubers than the wild-type strains (Fig. 5A). The maceration augmentation was significant for all strains except IFB0158. An increase of approximately 1.5-fold of maceration, compared with the wild-type strains, was observed after potato tuber infection with the pecT mutants of $D$. dadantii 3937 and IFB0099. The highest increase was observed in the pecT mutants of the less-virulent strains, IFB0223 (6.5-fold) and IFB0123 (3.1-fold). The pecT mutation had a stronger effect on the virulence on potato than mutations in the other negative regulators tested. The basal pectate lyase activity of all the pecT mutants was significantly elevated (Fig. 5B). These results are consistent with the increased ability of the pecT mutants to macerate potato tubers. The induced pectate lyase activity was also unregulated in most of the pecT mutants but was not statistically significant for IFB0158 (Fig. 5C). Protease activity did not change in most of the pecT mutants (Fig. 6A) but it was down regulated for IFB0158 and unregulated for IFB0223. As with $k d g R$ and pecS mutants, pecT mutants of IFB0223 exhibited a protease production not observed in the wild-type strain. The ability to chelate $\mathrm{Fe}^{3+}$ ions increased twofold for most of the $D$. solani pecT mutants but there was no change in the pecT mutants of $D$. dadantii 3937 and IFB0158 (Fig. 6B). Swimming capabilities significantly increased in all of the D. solani pecT mutants and were highest in the IFB0099 pec $T$ mutants, where high biosurfactant production was also noticed (Fig. 6C; data not shown).

\section{Phenotypes of the $D$. solani expR and expI mutants.}

We analyzed the ability of the mutants to produce signaling molecules of the AHL family. The production of AHL was not affected in the $k d g R$, pecS, or pecT mutants; like the wild-type strains, the mutants were able to produce only C6-HSL and C8-HSL. As expected, the expI mutants did not show any AHL production (data not shown). The expI and $\operatorname{expR}$ mutations, which influence QS, appeared to decrease the virulence of $D$. dadantii 3937 and D. solani strains on potato tubers (Fig. 5A; not shown for the 3937 expI mutant). The expI mutation had a greater influence on virulence, and the maceration decrease was significant for IFB0099, IFB0123, and IFB0223 expI mutants, with a reduction of two- to threefold compared with the corresponding wild-type strains. Considering the $\operatorname{expR}$ mutants, the virulence on potato was significantly decreased only for 3937 and IFB0123. The basal pectate lyase activity was not significantly altered by $\exp R$ and $\operatorname{expI}$ mutations (Fig. $5 B)$. The induced pectate lyase activity was significantly downregulated only in the IFB0123 expR mutant (Fig. 5C). Protease production was significantly downregulated in all the $\exp R$ and expI mutants, except in IFB0158 expI and in IFB0223, which has no protease activity (Fig. 6A). Swimming motility was significantly increased in $D$. dadantii $3937 \exp R$ mutants and $D$. solani IFB0158 expI mutants.

\section{DISCUSSION}

Plant-pathogenic pectinolytic bacteria are associated with the increasing economic losses in potato production due to the black-leg and soft-rot symptoms that develop in the field and during storage. Because they are able to survive at a low inoculum level $\left(10^{1}\right.$ to $10^{6}$ cells $\mathrm{g}^{-1}$ of peel) as saprophytes on the plant surface and in the intracellular spaces, they are difficult to detect and eradicate (Pérombelon 2002). A new group of strains from the Dickeya genus, D. solani, has emerged on potato cultivars in temperate climate (Degefu et al. 2013; Slawiak et al. 2009a and b; Toth et al. 2011; Van der Wolf et al. 2014).
A Protease activity $(24 \mathrm{~h})$
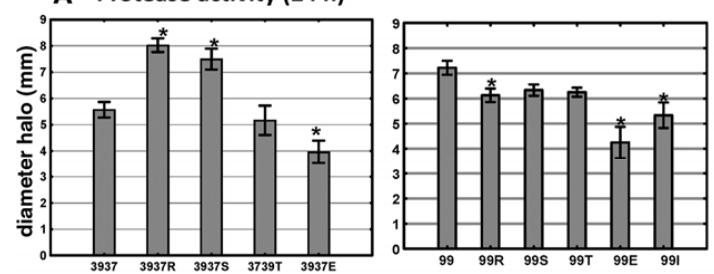

B Ability to chelate Fe ions ( $48 \mathrm{~h})$
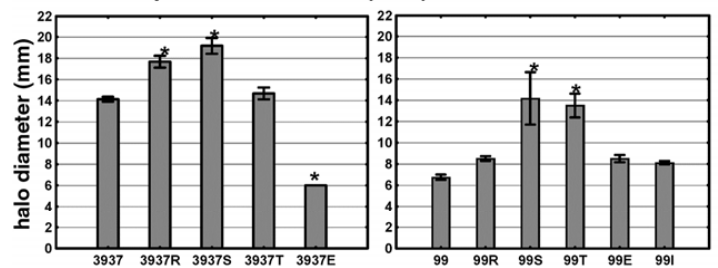

C Motility: swimming (24 h)
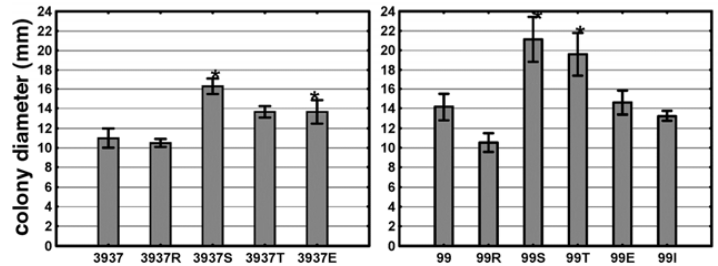
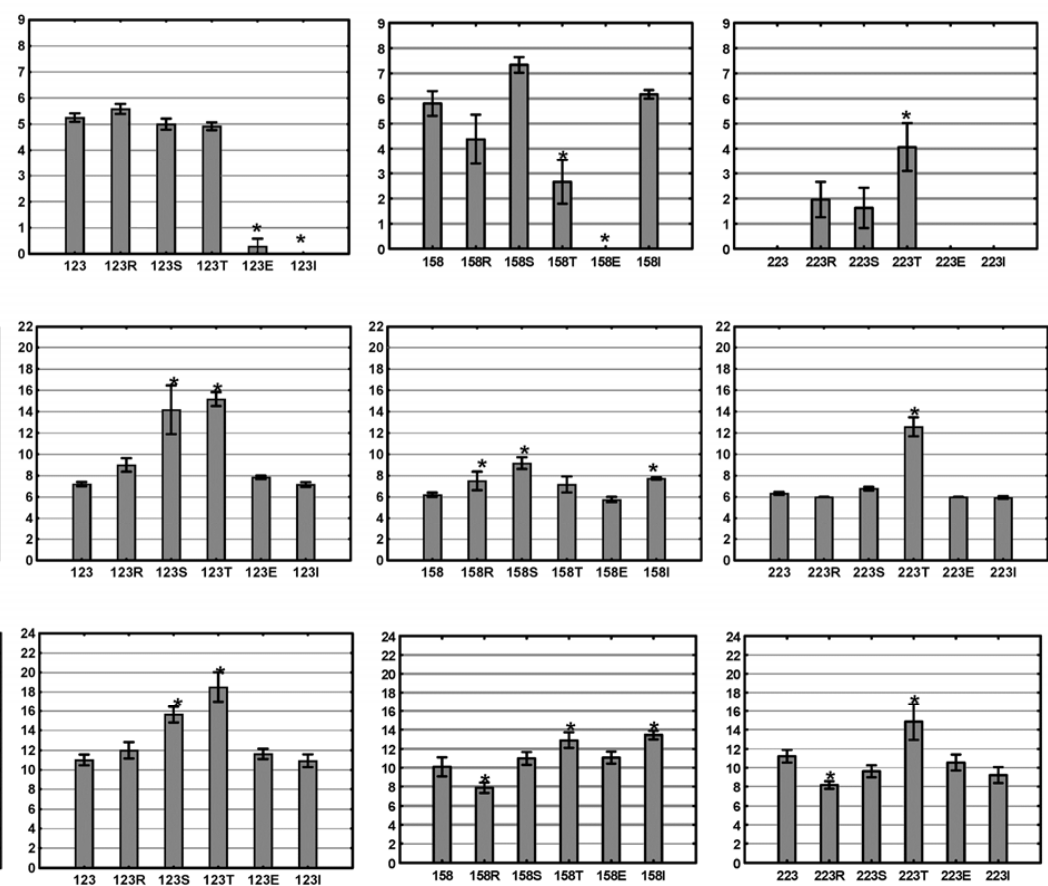
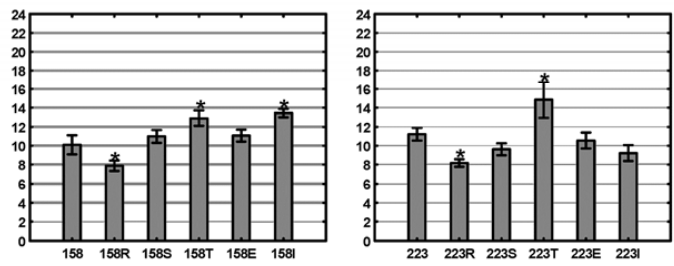

Fig. 6. Phenotypic characteristics of the mutants compared with the parental strains. A, Protease production was estimated by the diameter (mm) of the haloes observed on the detection plates $(n=3$; for each graph, $F=19.4,7.3,135.5,11.4$, and 7.2, respectively). B, Iron chelating capacity was estimated by the diameter $(\mathrm{mm})$ of the haloes observed around colonies $(n=3$; for each graph, $F=109.8,12.4,22.4,7.8,3$ and 8.8 , respectively). C, Motility was estimated by the diameter $(\mathrm{mm})$ of the spread of the colonies $(n=6$, for each graph, $F=7.1,7,10.8,7.3$, and 5.5, respectively). All the experiments were performed twice. Strains were Dickeya dadantii 3937 (3937); the D. solani strains IFB0099 (99), IFB0123 (123), IFB0158 (158) and IFB0223 (223); and the derived mutants indicated with $\mathrm{R}$ for the $k d g R:: \mathrm{Cm}$ mutants (e.g., 99R), S for the pecS::Cm mutants (e.g., 99S), T for the pecT::Cm mutants (e.g., 99T), E for

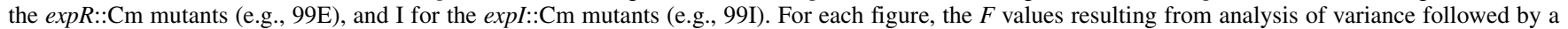
Fisher test are indicated above, with asterisks indicating mutants that differed significantly from the corresponding wild-type strain $(P<0.05)$. 
In recent years, most of the black-leg cases in The Netherlands were caused by the newly emerged $D$. solani (Czajkowski et al. 2009, 2012). In 2010, Scotland introduced a "zero tolerance" policy for the presence of Dickeya spp. in seed potato tubers (Toth et al. 2011). The same policy is gradually being applied in other countries, especially in North Africa (e.g., Egypt), where Dickeya spp. can cause much more severe losses in potato production than in Europe (Tsror et al. 2009).

Although it has been shown that $D$. solani can more easily spread through the plant vascular system and initiate the development of the disease from lower inoculum levels, and has a higher range of optimal temperature for disease development than the other potato pathogen, D. dianthicola (Czajkowski et al. 2010, 2013), little is known about the molecular mechanisms responsible for these characteristics. Because it has been shown from draft bacterial genome sequences (Pritchard et al 2013), DNA-DNA hybridization, multilocus sequence typing analysis, and matrix-assisted laser desorption ionization timeof-flight mass spectrometry protein mass fingerprints (Van der Wolf et al. 2014) that D. solani and D. dadantii species are close relatives, we wanted to investigate whether the regulators involved in the control of $D$. dadantii 3937 virulence are also important for $D$. solani virulence. The objective of this study was to examine the importance in $D$. solani virulence of three major negative transcriptional regulators (KdgR, PecS, and PecT) and of the QS system mediated by ExpR and ExpI. Because the virulence regulation is well documented in $D$. dadantii 3937, this strain and its mutants were used for comparison. To acquire a better understanding of the regulation of $D$. solani virulence, we used four strains that exhibit significant differences in the ability to cause disease symptoms. Mutants in each of the selected regulatory genes were constructed in the four D. solani strains. An extensive characterization of the phenotypic traits of the four D. solani wild-type strains and of the derived mutants was performed.

\section{Phenotypes of the wild-type strains.}

A study of several D. solani strains from Poland, different European countries, and Israel that exhibit differences in their ability to cause disease symptoms (Lojkowska et al. 2012) may reveal general effects, rather than strain-specific effects, and also indicate the extent of interstrain variation. Thus, four strains showing significant differences in virulence on potato and chicory were selected for this investigation. Despite the similarity in their genomic profiles (Fig. 2), the D. solani strains showed certain dissimilarities in many of the phenotypes tested (Figs. 3 and 4). Not surprisingly, the most striking differences were observed between IFB0099, the most virulent strain, and IFB0223, the least virulent strain.

The basal and induced levels of pectate lyase activity globally correlated with the level of maceration caused by the tested $D$. solani strains on chicory and potato, with maximum activity for the most virulent strains, IFB0099 and IFB0158, and lowest activity for the least virulent strain, IFB0223 (Fig. $4 \mathrm{~A}$ and $\mathrm{B}$ ). This is not surprising because pectate lyases are regarded as the main virulence factor of Dickeya spp. A high level of production in noninduced conditions may enable the strains to provoke symptoms more rapidly at the beginning of infection, before induction becomes really efficient (Hugouvieux-Cotte-Pattat et al. 1996). Together with a high growth rate, a high basal production of pectate lyases may be crucial in the initiation of the disease. As regards the production of proteases (Fig. 4C), slight differences were observed among the D. solani strains, with the exception of IFB0223, where no protease production was observed. Together with its low growth rate and low pectate-lyase level, the absence of protease production and a weak ability to chelate $\mathrm{Fe}^{3+}$ may contribute to the low virulence of strain IFB0223. In addition, strain IFB0223 was more sensitive to the phage phi-EC ${ }_{2}$ infection than the other $D$. solani strains.

It is noticeable that, among the $D$. solani strains tested, the most virulent strain, IFB0099, showed the highest growth rate, basal and induced pectate lyase activity, cellulase and protease production, and swimming ability (Fig. 4F), a capacity that could promote the spread of bacteria in the plant tissues. All these features are also known to contribute to the fitness of the bacteria in their environment, and IFB0099 seems to be the best "equipped" strain in this respect.

\section{Phenotypes of the regulatory mutants.}

Prior to the construction of the mutants, the presence of genes coding for the chosen regulators was verified using both PCR and analysis of the draft genome sequences of IFB0099 and IFB0223 (unpublished data). Gene conservation was complete in the two D. solani strains and all the orthologous genes were found to be $100 \%$ identical. Moreover, the orthologous genes of D. solani and D. dadantii 3937 shared the highest level of identity (92 to 95\%) in comparison with the genes of other Dickeya spp. whose genomes are available ( 75 to $88 \%$ identity between orthologous genes). The high degree of identity between $D$. dadantii and $D$. solani regulatory genes enabled us to construct $D$. solani mutants using a transduction procedure with phage phi$\mathrm{EC}_{2}$ previously described for $D$. dadantii 3937 (Résibois et al. 1984). In addition, this approach allowed for a subsequent comparison of the D. dadantii 3937 and $D$. solani mutants.

The phenotypic characterization of $D$. solani and $D$. dadantii 3937 mutants suggested that, overall, PecS, PecT, and KdgR proteins act in a similar manner in both species. These regulators repress the synthesis of different virulence factors (HugouvieuxCotte-Pattat et al 1996). The most important regulator of $D$. solani virulence appeared to be PecT. A clear increase in virulence was observed in the pecT mutants compared with the wild-type strains, and the maceration symptoms increased from 1.37- to 6-fold, depending on the D. solani strain. The smallest increase was observed for the most virulent strain (IFB0099) whereas the highest increase was observed for the weakly virulent strain (IFB0223). Similarly, basal and induced pectate lyase activity, the ability to chelate $\mathrm{Fe}^{3+}$ ions, and swimming motility were all upregulated in the $D$. solani pecT mutants. Although no protease production was detected in wildtype strain IFB0223, it become apparent after PecT, PecS, or $\mathrm{KdgR}$ inactivation, suggesting that the genes coding for protease production and secretion are present in the IFB0223 genome but they are strongly repressed. It is noticeable that pecT is the least well-conserved gene between $D$. solani and $D$. $d a$ dantii 3937 among those analyzed, with $92 \%$ identity for pecT, compared with 94 to $95 \%$ identity for $k d g R$, pecS, expI, or $\operatorname{expR}$. PecT was recently shown to be involved in the thermoregulation of pectate lyase genes (Hérault et al. 2014). It would be interesting to determine whether the PecT regulator plays a role in conferring the large optimal temperature range observed for $D$. solani virulence.

The repressor PecS also affects various virulence factors in D. solani. As previously shown in D. dadantii (Hommais et al. 2008), blue pigment production was observed in all the pecS mutants of $D$. solani. A correlation was observed between the level of blue pigment production and the virulence of the corresponding wild-type strain: the IFB0099 $\mathrm{pecS}$ mutant produced the largest amount of pigment and the IFB0223 pecS mutant produced the lowest amount of pigment. This blue pigment, indigoidin, may facilitate bacterial survival in plants because it is thought to act as a scavenger of free radicals, protecting the bacteria from the plant defense response (Hommais et al. 2008). 
Another interesting aspect of the regulation of $D$. solani virulence is the potential effect of QS. QS has been shown to have an important influence on the virulence of a vast number of plant-pathogenic bacteria (Mansfield et al. 2012). To analyze the role of QS in $D$. solani, we constructed mutants with a disruption of $\operatorname{expR}$ or $\operatorname{expI}$, the two genes responsible for QS in D. dadantii (Nasser et al. 1998). This system participates in pectate lyase regulation in $D$. dadantii 3937 but is considered to be of little importance for the virulence of this strain (Mhedbi-Hajri et al. 2011). However, QS is thought to play a role in D. zeae EC1 virulence (Hussain et al. 2008). Our results also suggest that QS is involved in the regulation of the $D$. solani virulence factors, although to a different level for each strain tested. The virulence of the $D$. solani expI mutants on potato decreased two- to threefold compared with the corresponding wild-type strains. Surprisingly, the $\exp R$ mutant of D. dadantii 3937 showed a similar reduction in virulence on potato tubers. The discrepancies between our results and those previously reported (Mhedbi-Hajri et al. 2011) may be due to the use of different plants to study the virulence of the strain 3937. We used potato tubers, whereas Mhedbi-Hajri and associates (2011) infected Saintpaulia ionantha and Arabidopsis thaliana. It is possible that QS is more important for potato infection. In $D$. solani, the expI mutation has a greater effect on virulence than the expR mutation, suggesting that AHL produced by ExpI may affect other receptors. No increase in swimming motility was observed in most of the QS mutants of $D$. solani but this effect was reported for D. zeae EC1 (Hussain et al. 2008). Moreover, no $\operatorname{expR}$ and $\operatorname{expI}$ homologs were found in the D. paradisiaca Ech703 genome. Thus, the effects of the ExpI-ExpR QS system seem to vary considerably depending on the Dickeya sp.

In conclusion, our study indicates that the major transcriptional regulators $\mathrm{KdgR}, \mathrm{PecS}$, and PecT play a similar role in the regulation of virulence in $D$. dadantii 3937 and in $D$. solani (i.e., they act as negative regulators of various factors involved in bacterial virulence). However, some disparities concerning the degree of control exerted by each regulator were observed between the two species and among the $D$. solani strains, with significant differences between the strongly and weakly virulent strains. In addition, this study indicates that the thermoregulator PecT is an essential regulator of $D$. solani virulence. Finally, this work demonstrates the role of QS in the modulation of Dickeya virulence, with clear variations depending on the Dickeya species and, perhaps, depending on the strains and on the host plants.

\section{MATERIALS AND METHODS}

\section{Bacterial strains.}

The wild-type Dickeya strains used in this study are $D$. $d a$ dantii 3937; four D. solani strains isolated in Poland, Germany, and The Netherlands; and other Dickeya strains listed in Table 1. Mutants in the genes coding for either one of the main virulence negative regulators $(k d g R$, pecS, and pecT) or the synthesis and perception of signaling molecules (expI and $\operatorname{expR}$ ) are listed in Table 1 . Three E. coli strains harboring plasmids were used for AHL detection (Table 1). The phi-EC 2 generalized transducing phage was used for transduction of the Dickeya strains (Résibois et al. 1984).

\section{Media and growth conditions.}

Bacteria were grown in LB (Sambrook et al. 2000) or M63 (Miller 1992) medium supplemented with glycerol (2 $\mathrm{g} \mathrm{liter}^{-1}$ ) or polygalacturonic acid $\left(4 \mathrm{~g} \mathrm{liter}^{-1}\right)$. When required, the media were solidified with agar $\left(15 \mathrm{~g} \mathrm{liter}^{-1}\right)$. D. dadantii or D. solani cells were incubated at 30 or $28^{\circ} \mathrm{C}$, whereas E. coli cells were grown at $37^{\circ} \mathrm{C}$. When required, $\mathrm{Cm}$ was added at a concentration of 20 or $5 \mu \mathrm{g} \mathrm{ml}^{-1}$.

\section{Genomic analyses.}

The genomic DNA from all strains was purified using a Genomic Mini AX Bacteria Kit (A\&A Biotechnology, Gdynia, Poland). The D. solani strains were analyzed using the repetitive-sequence-based REP-PCR with a pair of primers (REP 1 R-I and REP 2-I), as described by Versalovic and associates (1991). After electrophoresis, the band patterns of the different strains were compared.

The strains were also analyzed using PFGE after digestion of the genomic DNA with the XbaI restriction enzyme (Degefu et al. 2013).

For dnaX gene amplification, the PCR conditions and primers were as previously described (Slawiak et al. 2009b). PCR products were purified with a Clean-Up kit (A\&A Biotechnology) and sequenced from both primers by Genomed (Warsaw, Poland).

\section{Pathogenicity tests.}

Chicory leaves and potato tubers were inoculated as previously described (Hugouvieux-Cotte-Pattat 2004). Three chicory leaves were infected for each strain, using $10^{6} \mathrm{CFU}$ per inoculation site. After incubation in a dew chamber for $24 \mathrm{~h}$ at $30^{\circ} \mathrm{C}$, the length of rotted tissue was measured to estimate the disease severity. Six to nine potato tubers ('Charlotte') were inoculated with $5 \mu \mathrm{l}$ of bacterial suspension $\left(5 \times 10^{6} \mathrm{CFU}\right)$ using a sterile pipette tip. Following incubation in a dew chamber for $48 \mathrm{~h}$ at $30^{\circ} \mathrm{C}$, the weight of rotted tissue was measured to estimate the disease severity. The experiments were performed twice, with the number of replicates indicated in the figure legends.

\section{Growth curves.}

After inoculation with $50 \mu \mathrm{l}$ of the bacterial overnight culture, the growth of the Dickeya strains was followed in $2 \mathrm{ml}$ of $\mathrm{LB}$ medium at $28^{\circ} \mathrm{C}$ for approximately $20 \mathrm{~h}$. The cultures were performed in 24-well plates (Sarstedt, Nümbrecht, Germany) covered with an adhesive, transparent PCR seal to prevent evaporation of the medium. The optical density (OD) at 595 $\mathrm{nm}$ was measured automatically every $30 \mathrm{~min}$ in a Beckman Counter DTX800 multimode detector under the control of Multimode Analysis Software 3.1.0.1. For shaking between the measurements, three alternate methods were used: orbital, linear, and squared. After incubation, the cultures were diluted and plated on LB agar plates to determine the number of viable bacteria. The count results agreed with the results obtained from OD measurements. The experiments with two replicates were performed twice.

\section{Enzyme assays and detection.}

Pectate lyase activity was determined by monitoring spectrophotometrically the formation of unsaturated products from polygalacturonate at $235 \mathrm{~nm}$ (Tardy et al. 1997). Specific activity is expressed as micromoles of unsaturated products liberated per minute per milligram of bacterial dry weight. The pectate lyase activity was measured in bacterial cultures grown for $24 \mathrm{~h}$ at $28^{\circ} \mathrm{C}$.

Protease production was measured on medium containing skim milk (12.5 $\left.\mathrm{g} \mathrm{liter}^{-1}\right)$ after incubation for $24 \mathrm{~h}$ at $30^{\circ} \mathrm{C}(\mathrm{Ji}$ et al. 1987). The diameter of the clear halo around the colonies was measured.

The ability to produce cellulases was analyzed on M63 agar plates supplemented with glycerol at $2 \mathrm{~g} \mathrm{liter}^{-1}$ and carboxymethylcellulose at $10 \mathrm{~g} \mathrm{liter}^{-1}$, as described by Wood (1980). Bacterial suspension ( $2 \mu \mathrm{l}$ of $0.5 \mathrm{McFarland})$ was spotted onto this medium and incubated for $24 \mathrm{~h}$ at $28^{\circ} \mathrm{C}$. After incubation, 
the plates were flooded with Congo Red solution at $10 \mathrm{mg} \mathrm{ml}^{-1}$ for $10 \mathrm{~min}$ and washed for $5 \mathrm{~min}$ with $1 \mathrm{M} \mathrm{NaCl}$. The diameter of the clear halo around the colonies was measured. All experiments were performed twice, with the number of replicates indicated in the figure legends.

\section{Siderophore and biosurfactant production.}

Siderophore production was determined on chrome azurol S-agar plates (Schwyn and Neilands 1987) as described by Krzyzanowska and associates (2012). To visualize the production of biosurfactant, bacterial strains were inoculated by stabbing $0.7 \%$ semisolid agar plates, and the halo size of surfactant production was examined after growth for $24 \mathrm{~h}$ at $30^{\circ} \mathrm{C}$ (Hommais et al. 2008). The experiment was performed twice, with the number of replicates indicated in the figure legends.

\section{Motility assays.}

To assess the swarming motility on the surface of a solid medium, bacterial strains were inoculated onto $0.8 \%$ semisolid agar plates which were incubated at $28^{\circ} \mathrm{C}$ for $24 \mathrm{~h}$ (Harshey 2003). To assay the swimming motility inside the medium, the bacterial strains were inoculated into $0.3 \%$ semisolid agar plates and incubated at $28^{\circ} \mathrm{C}$ for $24 \mathrm{~h}$ (Harshey 2003). Inoculations were performed with $2 \mu$ of bacterial suspension $\left(10^{4}\right.$ $\mathrm{CFU} \mathrm{ml} \mathrm{m}^{-1}$ ). The experiment was performed twice, with the number of replicates indicated in the figure legends.

\section{AHL production.}

Bacteria were grown on LA plates (Sambrook et al. 2000). After $24 \mathrm{~h}$ of growth, the plates were covered with an overlay of $5 \mathrm{ml}$ of soft-top agar $\left(4 \mathrm{~g} \mathrm{liter}^{-1}\right)$ and $100 \mu \mathrm{l}$ of one of the $E$. coli indicator strains (HB101/pSB401, HB101/pSB534, or HB101/pSB1075) (Table 1). After overnight incubation at $28^{\circ} \mathrm{C}$, the plates were analyzed for chemiluminescence in ChemiDoc (Bio-Rad, Hercules, CA, U.S.A.).

For AHL isolation (Shaw et al. 1997), $5 \mathrm{ml}$ of an overnight culture (morpholinepropanesulfonic acid-buffered LB, pH 6.5) was extracted twice with ethyl acetate and the extract was dried under nitrogen gas. The pellet was resuspended in $50 \mu \mathrm{l}$ of ethyl acetate and 10-fold dilutions were used for further analysis. Thin-layer chromatography was performed on TLC RP18 plates; $1 \mu$ of a 10-fold dilution of each AHL extract was spotted and allowed to dry, and then an overlay was poured with soft-top agar containing one of the biosensor $E$. coli strain (Andresen et al. 2001; Winson et al. 1998). The experiments were performed twice, with three replicates for each strain.

\section{Sensitivity to bacteriophage phi-EC $\mathbf{C}_{2}$.}

The sensitivity of the D. solani strains to phi-EC ${ }_{2}$ was examined. Bacteriophage stocks were prepared by infecting $D$. $d a$ dantii 3937 and these stocks were used to infect each Dickeya strain. Bacterial lawns were prepared with $0.1 \mathrm{ml}$ of an over- night culture mixed with $5 \mathrm{ml}$ of soft agar $\left(4 \mathrm{~g} \mathrm{liter}^{-1}\right)$, poured onto LB supplemented with glucose at $2 \mathrm{~g}$ liter $^{-1}$ and $2 \mathrm{mM}$ $\mathrm{CaCl}_{2}$, a medium that improved the multiplication of the phages. Serial dilutions $\left(10 \mu \mathrm{l}\right.$; up to $\left.10^{-5}\right)$ of the phage stocks were spotted onto the bacterial lawns. The plates were incubated for $24 \mathrm{~h}$ at $30^{\circ} \mathrm{C}$. The transparent plaques under the drops of phage stock indicated the lysis of the tested bacterial strain by phage phi$\mathrm{EC}_{2}$. The experiment was performed three times.

\section{Construction of $D$. solani $k d g R$, pecS, pecT, expR, and $\exp I$ mutants.}

Because D. solani strains IFB0099, IFB0128, IFB0158, and IFB0223 are sensitive to phi-EC ${ }_{2}$, this phage was used to transfer mutations from $D$. dadantii to $D$. solani strains. First, phage stocks were prepared by infection of each $D$. dadantii mutant containing a regulatory mutation constructed by insertion of a cassette encoding $\mathrm{Cm}^{\mathrm{R}}$. Then, the phage stocks were used to infect $D$. solani strains or $D$. dadantii 3937 and the mutations were selected using $\mathrm{LB}+\mathrm{Cm}$ solid medium. In most cases, three different $\mathrm{Cm}^{\mathrm{R}}$ colonies were recovered from each transduction (Table 1). The correct insertion of the $\mathrm{Cm}$ cassette was verified using PCR with specific primers (Table 2 ). PCR reactions were carried out in a $25-\mu l$ reaction mixture containing $2 \mu \mathrm{l}$ of bacterial lysate. The reaction mixture contained $1 \times$ reaction buffer (Fermentas, Vilnius, Lithuania), 2.5 $\mathrm{mM} \mathrm{MgCl} 2,80 \mu \mathrm{M}$ each dNTP, $0.4 \mu \mathrm{M}$ each primer pair, and $1 \mathrm{U}$ of recombinant DNA Taq polymerase (Fermentas). PCR reactions were performed using a TGradient Biometra thermocycler at the following settings: a denaturation step $\left(94^{\circ} \mathrm{C}, 5\right.$ min); 30 cycles of denaturation $\left(94^{\circ} \mathrm{C}, 60 \mathrm{~s}\right)$, annealing $\left(50^{\circ} \mathrm{C}\right.$, $60 \mathrm{~s})$, and extension $\left(72^{\circ} \mathrm{C}, 120 \mathrm{~s}\right)$; with a final extension step $\left(72^{\circ} \mathrm{C}, 10 \mathrm{~min}\right)$. The amplified products were stained with $1 \mu \mathrm{l}$ of GelRed Nucleic Acid Stain at $0.5 \mu \mathrm{g} \mathrm{m}^{-1}$ and analyzed on $1.5 \%$ agarose (Prona, Madrid) gels in $0.5 \times$ Tris-borate-EDTA buffer. Gels were run at $100 \mathrm{~V}$ for approximately $40 \mathrm{~min}$ at room temperature. A 100-bp or 1-kb ladder (Fermentas) was used as a size marker.

\section{Data analysis.}

Comparisons were conducted between the phenotypic characteristics of the different wild-type strains as well as between the phenotypes of the mutants and that of corresponding wildtype strains. Statistical analysis (ANOVA followed by Fisher post-hoc test) was carried out using Statistica 10.0 StatSoft Polska. Data representing the mean values and error bars representing standard deviations are shown in the figures. The significance level used was $P<0.05$.

\section{ACKNOWLEDGMENTS}

We thank K. Smalla for the gift of the strain IFB0223 isolated in Germany. Appreciation is expressed to G. Condemine, V. Shevchik, and V.

Table 2. Primers designed and used in this study

\begin{tabular}{|c|c|c|c|}
\hline Gene & Name & Sequence $5^{\prime}-3^{\prime}$ & Product size $(b p)^{a}$ \\
\hline \multirow[t]{2}{*}{$k d g R$} & $\operatorname{kdgRf}$ & GCTCTAGACCGACAGACAATTCGACAGTC & \\
\hline & $\mathrm{kdgRr}$ & GCGGATCCTGTTTACGTCTGATGTCGATGG & 1,200 \\
\hline \multirow[t]{2}{*}{$\operatorname{pec} S$} & pecSf & GACGTATCACATCCTGTGAC & \\
\hline & pecSr & AAACCGGAACGTCTGACG & 1,021 \\
\hline \multirow{2}{*}{ pecT } & pecTf & AACATCAACACCAGGTATG & \\
\hline & pecTr & TAATGATTCATCTGTCGG & 991 \\
\hline \multirow[t]{2}{*}{$\exp R$} & expRf & CAATTTGGCTTTCCGATC & \\
\hline & expRr & CATTACACAGATAACAGACGC & 971 \\
\hline \multirow[t]{2}{*}{$\exp I$} & expIf & ATGTCAAATAACAAGCTGGATG & \\
\hline & expIr & ATGTCAAATAACAAGCTGGATG & 591 \\
\hline
\end{tabular}

${ }^{a}$ Primers were used to check the presence of the genes in the Dickeya solani genomes and their inactivation in the mutants constructed by transduction. Product size is given without the inserted antibiotic-resistance cassette (1.1 kb long). 
James for reading the manuscript. We thank A. Gwizdek-Wiśniewska for valuable help with statistical analysis. This work was supported by the European Social Fund within the framework of the Human Capital Operational Programme (LiSMIDoS) and National Science Center, Poland (NSC) DEC-2013/08/T/NZ9/01020 to M. Potrykus. It was also supported by grants from NSC 2013/08/M/NZ9/00974 and the French National Center for Scientific Research and the French Ministry of Higher Education and Research to UMR5240 and the Polish-French collaboration program Polonium (MNiSW-WWM-183-782-Z/MBA/10). Publication was supported by the European Commission from the FP7 project MOBI4Health.

\section{LITERATURE CITED}

Andersen, J. B. O., Hedorn, A., Hentzer, M., Eberl, L., Geisenberger, O., Christensen, B. B, Molin, S. O., and Givskov, M. 2001. Gfp-based Nacyl homoserine-lactone sensor system for detection of bacterial communication. Appl. Environ. Microbiol. 67:575-585.

Brady, C. L, Cleenwerck, I., Denman, S., Venter, S. N., RodrıguezPalenzuela, P., Coutinho, T. A., and De Vos, P. 2012. Proposal to reclassify Brenneria quercina (Hildebrand \& Schroth 1967) Hauben et al. 1999 into a novel genus, Lonsdalea gen. nov., as Lonsdalea quercina comb. nov., descriptions of Lonsdalea quercina subsp. quercina comb. nov., Lonsdalea quercina subsp. Iberica subsp. nov., and Lonsdalea quercina subsp. britannica subsp. nov., emendation of the description of the genus Brenneria, reclassification of Dickeya dieffenbachiae as Dickeya A new clade of Dickeya dadantii subsp. dieffenbachiae comb. nov., and emendation of the description of Dickeya dadantii. Int. J. Syst. Evol. Microbiol. 62:1592-1602.

Charkowski, A., Blanco, C., Condemine, G., Expert, D., Franza, T., Hayes, C., Hugouvieux-Cotte-Pattat, N., Lopez Solanilla, E., Low, D., Moleleki, L., Pirhonen, M., Pitman, A., Perna, N., Reverchon, S., Rodriguez-Palenzuela, P., San Francisco, M., Toth, I., Tsuyumu, S., Van der Walls, J., Van der Wolf, J., Van Gijsegem, F., Yang, C. H., and Yedidia, I. 2012. The role of secretion systems and small molecules in soft rot Enterobacteriaceae pathogenicity. Annu. Rev. Phytopathol. 50:425-449.

Condemine, G., and Robert-Baudouy, J. 1987. Tn5 insertion in $k d g R$, a regulatory gene of the polygalacturonate pathway in Erwinia chysanthemi. FEMS (Fed. Eur. Microbiol. Soc.) Microbiol. Lett. 42:3946.

Crepin, A., Barbey, C., Beury-Cirou, A., Helias, V., Taupin, L., Reverchon, S., Nasser, W., Faure, D., Dufour, A., Orange, N., Feuilloley, M., Heurlier, K., Burini, J., and Latour, X. 2012. Quorum sensing molecules produced by reference and emerging soft-rot bacteria (Dickeya and Pectobacterium spp.). PLoS One 7:35176.

Czajkowski, R., Grabe, G. J., and Van Der Wolf, J. M. 2009. Distribution of Dickeya spp. and Pectobacterium carotovorum subsp. carotovorum in naturally infected seed potatoes. Eur. J. Plant Pathol. 125:263-275.

Czajkowski, R., De Boer, W. J., Velvis, H., and Van der Wolf, J. M. 2010. Systemic colonization of potato plants by a soilborne green fluorescent protein-tagged strain of Dickeya sp. biovar 3. Phytopathology 100:134142.

Czajkowski, R., Perombelon, M. C. M., Van Veen, J. A., and Van der Wolf, J. M. 2012. Control of blackleg and tuber soft rot of potato caused by Pectobacterium and Dickeya species: A review. Plant Pathol. 60:9991013

Czajkowski, R., De Boer, W. J., Van der Zouwen, P. S., Kastelein, P., Jafra, S., de Haan, E. G., Van den Bovenkamp, G. W., and Van der Wolf J. M., 2013. Virulence of 'Dickeya solani' and Dickeya dianthicola biovar-1 and -7 strains on potato (Solanum tuberosum). Plant Pathol. 62:597610.

Degefu, Y., Potrykus, M., Golanowska, M., Virtanen, E., and Lojkowska, E. 2013. A new clade of Dickeya spp. plays a major role in potato blackleg outbreaks in North Finland. Ann. Appl. Biol. 162:231-241.

DeLindo, L., and French, E. R. 1981. Erwinia species attacking potato in the humid tropics of Peru. Fitopatologia 16:69-74.

Enard, C., Diolez, A., and Expert, D. 1988. Systemic virulence of Erwinia chrysanthemi 3937 requires a functional iron assimilation system. J. Bacteriol. 170:2419-2426.

Glasner, J. D., Yang, C. H., Reverchon, S., Hugouvieux-Cotte-Pattat, N., Condemine, G., Bohin, J. P., Van Gijsegem, F., Yang, S., Franza, T., Expert, D., Plunkett, G., M. J., Charkowski, A. O., Py, B., Bell, K., Rauscher, L., Rodriguez-Palenzuela, P., Toussaint, A., Holeva, M. C., He, S. Y., Douet, V., Boccara, M., Blanco, C., Toth, I., Anderson, B. D., Biehl, B. S., Mau, B., Flynn, S. M., Barras, F., Lindeberg, M., Birch, P. R., Tsuyumu, S., Shi, X., Hibbing, M., Yap, M. N., Carpentier, M., Dassa, E., Umehara, M., Kim, J. F., Rusch, M., Soni, P., Mayhew, G. F., Fouts, D. E., Gill, S. R., Blattner, F. R., Keen, N. T., and Perna, N. T.
2011. Genome sequence of the plant-pathogenic bacterium Dickeya dadantii 3937. J. Bacteriol. 193:2076-2077.

Harshey, R. M. 2003. Bacterial motility on a surface: Many ways to a common goal. Annu. Rev. Microbiol. 57:249-273.

Hassan, S., Shevchik, V. E., Robert, X., and Hugouvieux-Cotte-Pattat, N. 2013. PelN is a new pectate lyase of Dickeya dadantii with unusual characteristics. J. Bacteriol. 195:2197-2206.

Hérault, E., Reverchon, S., and Nasser W. 2014. Role of the LysR-type transcriptional regulator PecT and DNA supercoiling in the thermoregulation of pel genes, the major virulence factors in Dickeya dadantii. Environ. Microbiol. doi:10.1111/1462-2920.12198. Published online.

Hommais, F., Oger-Desfeux, C., Van Gijsegem, F., Ligori, S., Expert, D., Nasser, W., and Reverchon, S. 2008. PecS is a global regulator of the symptomatic phase in the phytopathogenic bacterium Erwinia chrysanthemi 3937. J. Bacteriol. 190:7508-7522.

Hugouvieux-Cotte-Pattat, N. 2004. The RhaS activator controls the Erwinia chrysanthemi 3937 genes rhiN, rhiT, and rhiE involved in rhamnogalacturonan catabolism. Mol. Microbiol. 51:1361-1374.

Hugouvieux-Cotte-Pattat, N., Condemine, G., Nasser, W., and Reverchon, S. 1996. Regulation of pectinolysis in Erwinia chrysanthemi. Annu. Rev. Microbiol. 50:213-257.

Hussain, B., Zhang, H., Xu, J., Liu, Q., Jang, Z., and Zhang, L. 2008. The acyl-homoserine lactone-type Quorum Sensing system modulates cell motility and virulence of Erwinia chrysanthemi pv. zeae. J. Bacteriol. 190:1045-1053.

Ji, J., Hugouvieux-Cotte-Pattat, N., and Robert-Baudouy J. 1987. Use of Mu-lac insertions to study the secretion of pectate lyases by Erwinia chrysanthemi. J. Gen. Microbiol. 133:793-802.

Kazemi-Pour, N., Condemine, G., and Hugouvieux-Cotte-Pattat, N. 2004. The secretome of the plant pathogenic bacterium Erwinia chrysanthemi. Proteomics 4:3177-3186.

Kepseu, W. D., Sepulchre, J. A., Reverchon, S., and Nasser, W. 2010. Toward a quantitative modeling of the synthesis of the pectate lyases, essential virulence factors in Dickeya dadantii. J. Biol. Chem. 285:2856528576.

Kotoujansky, A., Lemattre, M., and Boistard, P. 1982. Utilization of a thermosensitive episome bearing transposon Tn10 to isolate Hfr donor strains of Erwinia carotovora subsp. chrysanthemi. J. Bacteriol. 150:122-131

Krzyzanowska, D., Potrykus, M., Golanowska, M., Polonis, K., GwizdekWisniewska, A., Lojkowska, E., and Jafra, S. 2012. Rhizosphere bacteria as potential biocontrol agents against soft rot caused by various Pectobacterium and Dickeya spp. strains. J. Plant Pathol. 94:367-378.

Lojkowska E., Potrykus M., Golanowska M., and Jafra S. 2012. Phenotypic and genotypic characteristics of Dickeya strains isolated from potato in Poland. J. Biotechnol. 161S:9.

Mansfield, J., Genin, S., Magori, S., Citovky, V., Sriariyanum, M., Ronald, P., Dow, M., Verdier, V., Beer, S. V., Machado, M. A., Toth, I., Salmond, G., and Foster, G. D. 2012. Top 10 plant pathogenic bacteria in molecular plant pathology. Mol. Plant Pathol. 13:614-629.

Mhedbi-Hajri, N., Malfatti, P., Pédron, J., Gaubert, S., Reverchon, S., and Van Gijsegem, F. 2011. PecS is an important player in the regulatory network governing the coordinated expression of virulence genes during the interaction between Dickeya dadantii 3937 and plants. Environ. Microbiol. 13:2901-2914.

Miller, J. H. 1992. A Short Course in Bacterial Genetics: A Laboratory Manual and Handbook for Escherichia coli and Related Bacteria. Cold Spring Harbor Laboratory Press, Cold Spring Harbor, NY, U.S.A.

Nasser, W., and Reverchon, S. 2002. H-NS-dependent activation of pectate lyases synthesis in the phytopathogenic bacterium Erwinia chrysanthemi is mediated by the PecT repressor. Mol. Microbiol. 43:733-748.

Nasser, W., Bouillant, M. L., Salmond, G., and Reverchon, S. 1998. Char-

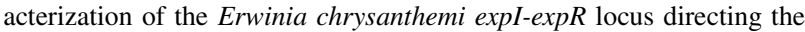
synthesis of two N-acyl-homoserine lactone signal molecules. Mol. Microbiol. 29:1391-1405.

Nasser, W., Shevchik, V. E., and Hugouvieux-Cotte-Pattat, N., 1999. Analysis of three clustered polygalacturonase genes in Erwinia chrysanthemi 3937 revealed an anti-repressor function for the PecS regulator Mol. Microbiol. 34:641-650.

Nasser, W., Dorel, C., Wawrzyniak, J., Van Gijsegem, F., Groleau, M., Deziel, E., and Reverchon, S. 2013. Vfm, a new quorum sensing system controls the virulence of Dickeya dadantii. Environ. Microbiol. 15:865880.

Pérombelon, M. C. M. 1992. Potato blackleg: Epidemiology, host-pathogen interaction and control. Neth. J. Plant Pathol. 98:135-146.

Pérombelon, M. C. M. 2002. Potato diseases caused by soft rot erwinias: An overview of pathogenesis. Plant Pathol. 51:1-12.

Praillet, T., Nasser, W., Robert-Baudouy, J., and Reverchon, S. 1996. Purification and functional characterization of PecS: A regulator of virulence factor synthesis in Erwinia chrysanthemi. Mol. Microbiol. 20:391-402. 
Pritchard, L., Humphris, S., Baeyen, S., Maes, M., Van Vaerenbergh, J., Elphinstone, J., Saddler, G., and Toth, I. K. 2013. Draft genome sequences of four Dickeya dianthicola and four Dickeya solani strains. Genome Announc. doi:10.1128/genomeA.00087-12. Published online.

Py, B., Bortoli-German, I., Haiech, J., Chippaux, M., and Barras F. 1991. Cellulase EGZ of Erwinia chrysanthemi: Structural organisation and importance of His 98 and Glu133 residues for catalysis. Prot. Eng. 4:325-333.

Raaijmakers, J., Paulitz, T., Steinberg, C., Alabouvette, C., and MoënneLoccoz, Y. 2009. The rhizosphere: A playground and battlefield for soilborne pathogens and beneficial microorganisms. Plant Soil 321:341361 .

Résibois, A., Colet, M., Faelen, M., Schoonejans, T., and Toussaint, A. 1984. Phi-EC 2 , a new generalized transducing phage of Erwinia chrysanthemi. Virology 137:102-112.

Reverchon, S., and Nasser, W. 2013. Dickeya ecology, environment sensing and regulation of virulence programme. Environ. Microbiol. Rep. 5:622-636.

Reverchon, S., Bouillant, M. L., Salmond, G., and Nasser, W. 1998. Integration of the quorum-sensing system in the regulatory networks controlling virulence factor synthesis in Erwinia chrysanthemi. Mol. Microbiol. 29:1407-1418

Rodionov, D. A., Gelfand, M. S., and Hugouvieux-Cotte-Pattat, N. 2004. Comparative genomics of the KdgR regulon in Erwinia chrysanthemi 3937 and other $\gamma$-proteobacteria. Microbiology 150:3571-3590.

Sambrook, J., Fritsch, E. F., and Maniatis, T. 2000. Molecular Cloning: A Laboratory Manual, 3rd ed. Cold Spring Harbor Laboratory Press, Cold Spring Harbor, NY, U.S.A.

Samson, R., Legendre, J. B., Christen, R., Fischer-Le Saux, M., Achouak, W., and Gardan, L. 2005. Transfer of Pectobacterium chrysanthemi (Burkholder et al. 1953) Brenner et al. 1973 and Brenneria paradisiaca to the genus Dickeya gen. nov. as Dickeya chrysanthemi comb. nov. and Dickeya paradisiaca comb. nov. and delineation of four novel species, Dickeya dadantii sp. nov., Dickeya dianthicola sp. nov., Dickeya dieffenbachiae sp. nov. and Dickeya zeae sp. nov. Int. J. Syst. Evol. Microbiol. 55:1415-1427.

Schwyn, B., and Neilands, J. B. 1987. Universal chemical assay for the detection and determination of siderophores. Anal. Biochem. 160:46-56.

Shaw, P. D., Ping, G., Dalys, L., Cha, C., Cronan, J. E., Jr, Rinehart, K. L., and Farrand, S. K. 1997. Detecting and characterizing N-acyl-homoserine lactone signal molecules by thin-layer chromatography. Proc. Natl. Acad. Sci. U.S.A. 94:6036-6041.

Slawiak, M., Lojkowska, E., and Van der Wolf, J. M. 2009a. First report of bacterial soft rot on potato caused by Dickeya sp. (syn. Erwinia chrysanthemi) in Poland. Plant Pathol. 58:794.
Slawiak, M., Van Beckhoven, J. R. C. M., Speksnijder, A. G. C. L., Czajkowski, R., Grabe, G., and Van der Wolf, J.M. 2009b. Biochemical and genetical analysis reveal a new clade of biovar 3 Dickeya spp. strains isolated from potato in Europe. Eur. J. Plant Pathol. 125:245-261.

Surgey, N., Robert-Baudouy, J., and Condemine, G. 1996. The Erwinia chrysanthemi pecT gene regulates pectinase gene expression. J. Bacteriol. 178:1593-1599.

Tamaki, S. J., Gold, S., Robeson, M., Manulis, S., and Keen, N. T. 1988 Structure and organization of the pel genes from Erwinia chrysanthemi EC16. J. Bacteriol.170:3468-3478.

Tardy, F., Nasser, W., Robert-Baudouy, J., and Hugouvieux-Cotte-Pattat, N. 1997. Comparative analysis of the five major Erwinia chrysanthemi pectate lyases: Enzyme characteristics and potential inhibitors. J. Bacteriol. 179:2503-2511.

Toth, I. K., Van der Wolf, J. M., Saddler, G., Lojkowska, E., Hellias, V., Pirhonen, M., Tsros, L., and Elphinstone, J. 2011. Dickeya species: An emerging problem for potato production in Europe. Plant Pathol. 60:385-399.

Tsror, L. (Lakhim), Erlich, O., Lebiush, S., Hazanowsky, M., Zig, U., Slawiak, M., Grabe, G., Van der Wolf, J. M., and Van der Haar, J. J. 2009. Assessment of recent outbreaks of Dickeya sp. (syn. Erwinia chrysanthemi) slow wilt in potato crops in Israel. Eur. J. Plant Pathol. 123:311-320

Versalovic, J., Koeuth, T., and Lupski, J. R. 1991. Distribution of repetitive DNA sequences in eubacteria and application to fingerprinting of bacterial genomes. Nucleic Acids Res. 19:6823-6831.

Van der Wolf, J. M., Nijhuis, E. H., Kowalewska, M. J., Saddler, G. S., Parkinson, N., Elphinstone, J. G., Pritchard, L. Toth, I. K., Lojkowska, E., Potrykus, M., Waleron, M., de Vos, P., Cleenwerck I., Pirhonen, M., Garlant, L., Helias, V., Pothier, J. F., Pflüger, V., Duffy, B., Tsror, L., and Manulis, S. 2014. Dickeya solani sp. nov., a pectinolytic plan pathogenic bacterium isolated from potato (Solanum tuberosum). Int. J. Syst. Evol. Microbiol. doi:10.1099/ijs.0.052944-0. Published online.

Weinert, N., Meincke, R., Gottwald, C., Radl, V., Dong, X., Schloter, M., Berg, G., and Smalla, K. 2010. Effects of genetically modified potatoes with increased zeaxanthin content on the abundance and diversity of rhizobacteria with in vitro antagonistic activity do not exceed natural variability among cultivars. Plant Soil 326:437-452.

Winson, M. K., Swift, S., Fish, L., Throup, J. P., Jørgensen, F., Chabra, S. R., Bycroft, B. W., Williams, P., and Stewart, G. S. 1998. Construction and analysis of luxCDABE-based plasmid sensors for investigating $\mathrm{N}$ acyl homoserine lactone-mediated quorum sensing. FEMS (Fed. Eur. Microbiol. Soc.) Microbiol. Lett. 163:185-192.

Wood, P. J. 1980. Specificity in the interaction of direct dyes with polysaccharides. Carbohydr. Res. 85:271-287. 